\title{
Editorial
}

\section{Structural Recession in the U.S.A.}

The recession (or depression) in the U.S. is finally being taken seriously. It is not a cyclical fluctuation and it is not going to be "resolved" by traditional macroeconomic tinkering and "fine-tuning". This recession reflects unprecedented, long-term powershifts in both micro- and macrostructures and thus it is a model of what is soon to emerge in all mature and developed economies, including Japan.

Its major new characteristic is the decline in jobgenerating capacity of the so-called service sector. In the 1980s, services in the U.S. added 21 million jobs and employed almost four out of five workers. Some 70 percent of the total workforce is in the services. Some "fast-draw" analysts started talking about a "service economy", others attempted to emulate the U.S. services domination in their own economies, economists took steady growth of services for granted.

However, services are no different from any other economic sector, like agriculture or manufacturing, which went into the irreversible loss of employment decades ago. The accelerating productivity growth rates in those sectors have caused the steady decline in their job-generating capacity. The service sector is simply following the pattern: increasing automation, increasing productivity, global competitive pressures, high relative costs and overgrown hierarchies are annihilating its own employment opportunities.

Nobody in his right mind would call for an increased employment in the agriculture as a way of salvaging the economy. Very few intellectual excentrics would still hope for any extensive employment opportunities in the manufacturing sector. Yet, many are still prepared to call for expanding the services employment opportunities, as if the productivity, demand and global competition do not matter. Somehow, the message is not getting

IOS Press

Human Systems Management 11 (1992) 1-4 through, no matter how and how many times restated: The service sector employment boom is over, it is done with, it is never to return. Computerization, automation, consumers' pressure and productivity growth will take care of that, as they did in the agriculture and manufacturing some time ago.

There is no final, stable state for an economy, especially not the "service economy" state-pattern, which has in fact been the shortest sectoral domination so far: it has lasted only about 40 years.

In Fig. 1 we present a sketch of the general sectoral dynamics from which there is no escape and which all economies, slowly or rapidly, sooner or later, are bound to follow. Each sector has to emerge, grow, persist, stagnate, decline and dissipate in terms of its employment generating capacity. It has never happened otherwise and it never will.

The high-productivity growth sectors are emerging and dissipating first, the low-productivity growth sectors (like services) are completing their cycle only now. Yet, new sectors are not emerging because we have already exhausted the potential of low-productivity growth sectors and zero-or negative-productivity growth "sectors" (unemployment, welfare) cannot sustain any economy for too long. The last bar of Fig. 1 suggests the hypothetical unsustainable employment structure in the U.S. about the year 2000 .

The differential productivity growth rates in different sectors are accompanied by essentially uniform growth rates in wages and salaries across all sectors. This simple empirical fact, often ignored and rarely explained, implies that the costs and prices grow relatively faster in low-productivity sectors and relatively slower in high-productivity sectors. In other words, in mature economies, the prices of food and manufactured goods are getting relatively cheaper and the prices of services are getting relatively more expensive. In slow-developing, 


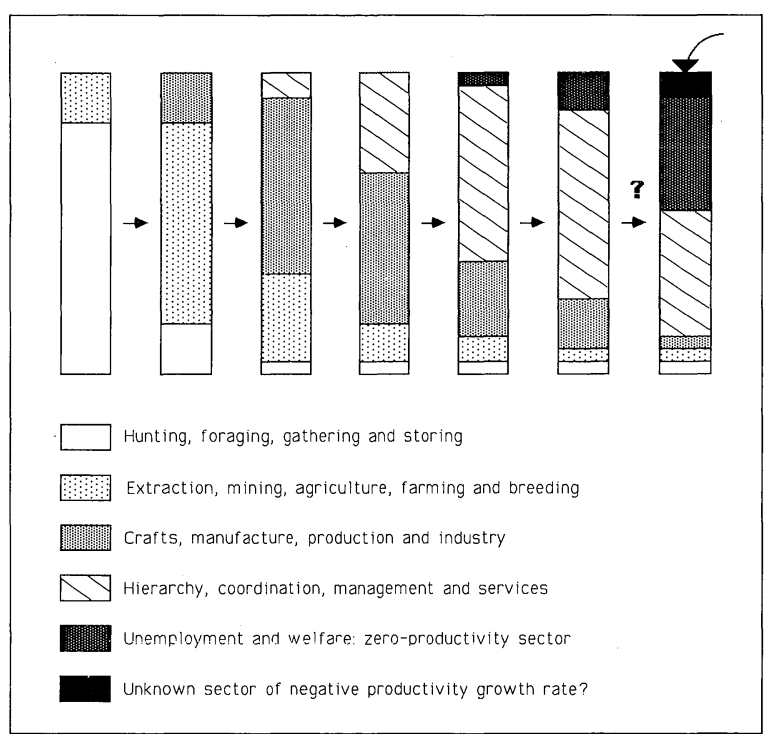

Fig. 1. Sectoral evolution and differentiation (in a rapidly maturing economy): Each sector, including services, emerges, stagnates and declines.

laggard economies of the Third World it is still the other way around: food and manufactured goods are most expensive while services remain relatively the cheapest. That is, in developed countries, chicken, bread, computers and cars are getting cheaper, while insurance, health care and education are skyrocketing without any quality, productivity or availability improvements.

This fundamental systemic disharmony, between differential productivity growth rates on one hand and the uniform wage/salary growth rates across sectors on the other hand, points to a self-organizing, spontaneous mode of resolving the tension. Rational economic agents will exhibit and support the tendency towards substituting relatively cheaper capital-intensive manufactured goods for relatively dearer labor-intensive services. Consumers will tend to use goods instead of services wherever economical and possible, while the producers will tend to respond by supplying them with goods instead of services wherever economical and possible.

As a result of this collectively rational decision making, one shall observe the predominance of automated teller machines instead of bank tellers, self-service gas stations instead of full-serve stations (except where prohibited by law), self-driving

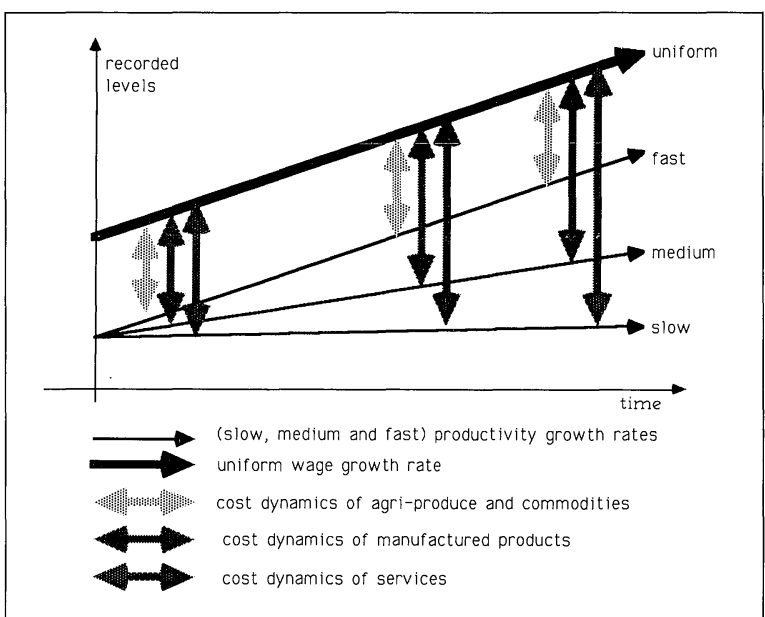

Fig. 2. Price gap: Differential sectoral productivity growth rates, combined with the uniform wage growth in the whole economy, causes the prices to grow faster in the "lagging" sectors.

instead of chauffers, do-it-yourself pregnancy kits rather than hospital test services, self-handled optical scanners rather than cashier services and personal computers instead of centralized mainframes.

In other words, self-service and do-it-yourself activities are replacing the traditional, other-person - delivered services at an increasingly accelerating rate, in spite of business and governmental political countermoves. Mature economies are entering the era of self-service and do-it-yourself societies.

Self-service activities are characterized by high efficiency: they can be delivered when, where and at what quality the user desires, at lower costs and at a shorter time. They require user-friendly requisite product with easy-to-use, reliable instructions and support, sufficient time and high costs of alternative services. All these conditions are present in mature economies. Do-it-yourself industries are the fastest growing parts of the U.S. economy, virtually impervious to recession or depression.

Human Systems Management has, from its very beginning, identified the self-service trends and supported research in that direction, see [1] and [2]. This editor has warned very early of the upcoming service sector decline [3]. Nothing has been changed in the argument: J. Skolka first stated it in 1976. That would have given us almost 20 years to prepare and get ready, to anticipate.

It is natural that in a reactive society only a few 
policy makers pay sufficient attention to the longterm trends: virtually nobody prepares for the future. The short-term, year-to-year fluctuations are just about the right interest span of most economists and politicians. The proactive society, which would be fully in charge and in full understanding of its own economic system and institutions, has not yet emerged.

The self-service society is characterized by increasing autonomy of workers and consumers, growth of work-at-home, telecommuting, selfemployment, community self-help, home office, part-time and seasonal work, early retirement, barter and exchanges networking, flexible workhours, self-management, decline of supervisory "services", and decentralized self-reliance, among others.

In the U.S. one can even see the emergence of self-serve auto show rooms and true: cars do sell themselves, especially the good ones. In Japan one can see an incredible proliferation of vending machines, dispensing not only goods but also information. The self-service is expanding and we are quickly learning how to deliver it, how to use it and how to harness it.

In the Self-service society there is no conspicuous increase in leisure, because traditional leisure activities are themselves overpriced services, being substituted for by self-service. There is a tendency for job-holders to work even longer hours although the overall amount of time worked per person is declining. The time spent for self-service and do-ityourself activity is one of the few expanding categories of economic activities.

Households are again becoming primary investment/production units, producers and consumers are merging into "prosumers". Integration is replacing specialization, vertical hierarchies are being flattened into self-managing heterarchies, knowledge has become the most important form of capital. Democracy and autonomy are venturing pass the factory gates, into the companies and inside the enterprises. The Self-service society has been taking the roots in the U.S.A. during the past 20 years. But only a few, only those with the right institutional and historical eyes, can see.

It is unfortunate that this structural upheaval has to coincide with the efforts of post-socialist econo- mies to move towards free markets. Many of them are wrongly and even suicidally devastating their primary sectors of agriculture and manufacturing while hoping to leapfrog into the "service society", of the U.S. type, precisely at the time of its demise. Financial, legal and speculative services are totally inappropriate for Russia and Eastern Europe; they lack their agricultural and manufacturing base. Reforms in Eastern Europe should have started with the agriculture and manufacturing, not with the financial services, money markets and neo-communist tinkering with the prices. It is too late now: no "service economies" are going to emerge on the agricultural/industrial ruins.

But, on a different level, it may be also too late for the U.S.: We have not and will not be able to sustain our service industry. Our rapprochement with the chaotic, backwarded Russia and political " "bashing" of highly developed, proven and reliable capitalistic allies is just one of the signs of the state adrift.

It is also disappointing that the 1992 political campaign in the U.S. has not recognized and grasped these realities. Instead of acknowledging and amplifying the powerful spontaneous trends towards self-reliance of modern pioneers, politicians are still selling the Big State: cutting taxes, increasing taxes, increasing regulation, limiting regulation ... Some even hope, that workers' and managers' productivity and knowledge will be magically restored by simply denying their low levels and by threatening those who point out the obvious fact. Unfortunately, none of this will fly and none of this will even stand.

New generations of politicians, businessmen and managers are about to emerge in the U.S., replacing those who are expectedly tired in their thinking, overwhelmed by the changes, elderly in their habits and too predictable in their action. Paradigm shifts occur not only in scientific research, but also in competitive management action. This paradigm shift has started some decades ago, perhaps with the commanding move from the overcautious "Just-incase" to the daring and exhilirating "Just-in-time". Some have missed this spaceship which is not going to fly by again: it went thataway.

This U.S. recession is nothing less than fundamental structural realignment of socioeconomic 
forces pulling away from specialization and division of labor and pushing towards reintegration of task, labor and knowledge, towards the autonomy of producers/consumers and towards the renewed self-service, self-help and self-reliance of citizens.

Traditional economics and traditional politics shall not do.

\section{References}

[1] Kochen, M. and M. Zeleny (1981): Self-service aspects of health maintenance: assessment of current trends, Human Systems Management, 2(4): 259-267.

[2] Zeleny, M. (1980): Towards a self-service society, Human Systems Management, Editorial, 1(1): 77.

[3] Zeleny, M. (1979): The Self-Service Society: A New Scenario of the Future, Planning Review, 7(3): 3-7, 37-38.

Milan ZELENY

Graduate School of Business Fordham University at Lincoln Center New York, NY 10023 